\title{
ESTUDO DA DESNATURAÇÃO PROTEICA NO MEXILHÃO (Mytilus edulis) DURANTE TRATAMENTO TÉRMICO
}

\author{
M. DE LIMA ${ }^{1}$, L. C. B. CHRISTENSEN ${ }^{2}$, L. KRAMER ${ }^{2}$, B. T. ROTABAKK ${ }^{2}$, A. R. MONTEIRO ${ }^{1}$, \\ L. A. LERIN ${ }^{1}$ e M. SIVERTSVIK ${ }^{2}$ \\ ${ }^{1}$ Universidade Federal de Santa Catarina, Departamento de Engenharia Química e Engenharia de \\ Alimentos \\ ${ }^{2}$ Nofima, Departamento de Processamento Tecnológico, Stavanger, Noruega. \\ E-mail para contato: marielidelima@yahoo.com.br
}

RESUMO - Foram investigadas as alterações nas propriedades físicas de mexilhões submetidos ao tratamento térmico em forno convectivo a $100^{\circ} \mathrm{C}$ até $6 \mathrm{~min}$, onde a cada minuto analisaram-se a perda de água, umidade, exsudação e avaliação visual. Os mexilhões "in natura" e cozidos foram analisados por Calorimetria Diferencial de Varredura (DSC), de $30^{\circ} \mathrm{C}$ até $115^{\circ} \mathrm{C}$ e composição proteica de baixo e alto peso molecular (SDS-PAGE). Alterações na cor e redução de volume foram identificadas nos mexilhões durante os períodos de cocção. Houve diferenças entre os picos de desnaturação proteica, na faixa de temperatura de 50 a $65^{\circ} \mathrm{C}$ para o mexilhão fêmea e entre 50 a $65^{\circ} \mathrm{C}, 85^{\circ} \mathrm{C}$ a $95^{\circ} \mathrm{C}$ e $95^{\circ} \mathrm{C}$ a $110^{\circ} \mathrm{C}$ para o macho. Predominaram as proteínas de baixo peso molecular e as diferenças encontradas foram individuais e não foram evidenciadas entre os gêneros. Recomenda-se realizar um tratamento térmico suficiente para a remoção da carne para evitar alterações nas características físicas e sensoriais em mexilhões.

\section{INTRODUÇÃO}

O mexilhão azul (Mytilus edulis) é um molusco bivalve importante para a economia europeia e norueguesa, assim como no sul do Brasil. O cultivo do mexilhão é uma das modalidades mais produtivas, devido ao baixo custo de produção e a facilidade no manejo, além do apelo nutricional (Dias et al., 2010). Os mexilhões são conhecidos como um alimento saudável, por ter alto valor nutricional, sendo rico em proteína, similar àquela encontrada em leite e ovos, teores baixos de gordura e colesterol e uma excelente fonte de Ômega-3 (Oliveira et al., 2011).

A comercialização do mexilhão ocorre principalmente na forma in natura, sem casca, marinado e congelado. O produto também é comercializado na versão desconchada, refrigerada, embalada em embalagens flexíveis e defumada e este pode passar por um tratamento térmico para remoção da carne das conchas, que, além de extrair a carne dos moluscos, serve para reduzir a carga microbiana e inibir o crescimento de bactérias, parasitas e vírus patológicos ao homem (Furlan et al., 2007; Lima, 2014). No entanto, o tratamento térmico promove transformações na carne, que influenciam diretamente nas propriedades físicas do mexilhão e também na aceitabilidade do produto para consumo. 
Alterações no mexilhão após o tratamento térmico, como perda de água, observadas pela variação na umidade e pela exsudação no interior das embalagens são resultantes da desnaturação proteica e o encolhimento do tecido conjuntivo, devido às alterações no ponto isoelétrico das proteínas, além de outros componentes solúveis que são perdidos (Erdogdu et al., 2004; Masniyom et al., 2011). Outro fenômeno é a solubilização parcial do colágeno em virtude da temperatura de cocção, e nesta etapa, a proteína flui para fora do músculo com a água, e pode formar uma gelatina mediante o resfriamento do exsudado (Pulgar et al., 2012). Em relação ao mexilhão não há informação na literatura a respeito da composição do exsudado, tampouco se a quantidade de proteínas solúveis representa uma perda significativa no processo e como essas alterações influenciam nas características do mexilhão.

Assim, a interpretação de fenômenos de desnaturação proteica e perda de água permite visualizar os substratos disponíveis para a degradação proteolítica que ocorre em mexilhões durante o armazenamento, resultando das reações enzimáticas e da atividade de micro-organismos. $\mathrm{O}$ entendimento desses fenômenos pode contribuir na manutenção da qualidade final dos produtos cárneos, quando submetidas a processos térmicos minimizando as mudanças das proteínas miofibrilares, que influenciam na textura do produto e durante o armazenamento (Paredi et al., 1994). O objetivo deste trabalho foi estudar as alterações nas propriedades físicas e o mecanismo da desnaturação proteica nos mexilhões submetidos ao tratamento térmico.

\section{MATERIAL E MÉTODOS}

\subsection{Tratamento térmico nos mexilhões}

Os mexilhões foram submetidos ao tratamento térmico a $100{ }^{\circ} \mathrm{C}$ por tempo de $1,2,4$ e 6 min, em diferentes períodos, usando um forno de convecção de vapor (Zanussi FCV/E10L, Pordenone, Itália). As amostras foram resfriadas até $1^{\circ} \mathrm{C}$ por 20 minutos em uma câmara fria (Metos BC161, Metos Norway, Oslo, Noruega) com alta velocidade de ar antes da remoção da carne, manualmente, das conchas. Os mexilhões desconchados foram analisados em cada tempo de cocção, quanto às suas propriedades físicas e térmicas descritas a seguir.

\subsection{Avaliação das propriedades físicas}

\section{Perda de água}

A perda de água durante a coação foi determinada gravimetricamente, pela diferença de massa entre o mexilhão inteiro cru (a água livre acumulada dentro da concha) que foi removida pelo estímulo à abertura da concha dos mexilhões vivos e do mexilhão cozido nos diferentes períodos, em triplicata, expresso em percentual $(\%)$.

O conteúdo de água foi determinado em estufa a $105^{\circ} \mathrm{C}$ durante $18 \mathrm{~h}$ de acordo com Skipnes et al. (2007), até peso constante.

A exsudação no interior das embalagens foi avaliada nos mexilhões embalados em bandejas no mesmo dia de processamento, quantificada gravimetricamente, onde a massa do exsudado (g) foi 


\section{9 a 22 de outubro de 2014 \\ Florianópolis/SC}

dividida pela massa inicial do produto $(\mathrm{P})$ e relatado como uma percentagem $(\%)$.

\subsection{Propriedades térmicas}

\section{Calorimetria diferencial de varredura (DSC) e eletroforese (SDS-Page)}

Para obtenção do comportamento da estrutura do mexilhão após o tratamento térmico, utilizouse a técnica de Calorimetria Diferencial de Varredura (DSC). $20 \mathrm{mg}$ de amostras do manto in natura e cozido de mexilhões machos e fêmeas, foram pesados em panelas de aço inox com $\varnothing 7 \mathrm{~mm}$ para média pressão em equipamento DSC1 (Mettler Toledo, Schwerzenbach, Suíça), onde foram realizadas varreduras de $30^{\circ} \mathrm{C}$ até $115^{\circ} \mathrm{C}$ (Gorinstein et al., 2006).

A identificação das proteínas de alto e baixo peso molecular foi realizada por eletroforese SDSPAGE. Para tal, $2 \mathrm{~g}$ de amostras de mexilhão foram previamente homogeneizadas em $8 \mathrm{~mL}$ tampão de pescado, por $1 \mathrm{~min}$ a $13.000 \mathrm{rpm}$ em Ultra Turrax. A mistura homogeneizada foi diluída 10 vezes em tampão de pescado e foi reservada para as análises. A determinação das proteínas foi realizada em nanoespectrofotômetro com faixa de A280 nm. As amostras foram diluídas novamente (20 vezes) em solução tampão de pescado, e adicionadas a proteína Methoden-UV $(4 \mu \mathrm{L})$. Usou-se o fator de correção para A280 nm $(1,550)$ e a diluição ajustada para diluição de 20 vezes. As amostras estoque foram ajustadas de $3,0 \mathrm{mg} / \mathrm{mL}$ em $100 \mu \mathrm{l}$ com tampão em tubos eppendorf. Foram adicionados $5 \mu 1$ de $\beta$ mercaptoetanol e as amostras foram armazenadas no refrigerador.

Para a análise do gel, este foi lavado em água MiliQ, e as amostras foram misturadas com tampão de Laemmli $95 \mu \mathrm{l}$ (BioRad) concentração de $1,5 \mathrm{mg} / \mathrm{mL}$. As amostras foram aquecidas em banho-maria a $85^{\circ} \mathrm{C} / 2 \mathrm{~min} .800 \mathrm{~mL}$ de tampão foi diluído uma vez $(80 \mathrm{~mL}$ tampão de corrida diluído 10 vezes e 760 $\mathrm{mL}$ de água MilliQ) e $10 \mu \mathrm{l}$ de amostra foram aplicados nos espaços da placa de gel (capacidade de 15 $\mu \mathrm{g}$ de proteína). $5 \mu \mathrm{l}$ proteína padrão foi adicionada. A corrida para análise do gel foi a $200 \mathrm{~V}$ durante 30-40 min. Após a análise por eletroforese, as caixas com o gel foram lavadas com água Milli-Q e descartado, e apenas os géis permaneceram.

\section{RESULTADOS E DISCUSSÃO}

\subsection{Variação das propriedades físicas durante o tratamento térmico}

Os diferentes tempos de tratamento térmico empregados promoveram transformações físicas nos mexilhões, tais como descolamento da carne da concha, bem como seu encolhimento, resultando em redução no volume e alterações na cor da carne, característicos do produto cozido. A Figura 1 mostra o aspecto visual dos mexilhões submetidos ao tratamento térmico por 1, 2, 4 e 6 min, respectivamente. Visualmente foi observado que o descolamento e o encolhimento da carne aumentou gradativamente com o aumento do tempo de tratamento térmico. O tratamento ideal deve assegurar que mudanças indesejáveis sejam evitadas nas frações proteicas e lipídicas, além de garantir que os micro-organismos alvo sejam eliminados e/ou reduzidos. Outra característica desejável é a fácil remoção da carne sem perder suas características de suculência. Outros trabalhos relataram o uso de tratamento térmico com ar saturado com água a $100{ }^{\circ} \mathrm{C}$ durante 3 minutos, e foi possível obter a $100 \%$ de abertura das conchas 
em mexilhão (Azanza et al., 2005). A alteração de cor foi percebida, porém houve dificuldade em se estabelecer a mudança global de cor nos mexilhões, devido à heterogeneidade da matéria prima, onde a padronização da cor do produto in natura em relação aos produtos cozidos demonstrou pouca uniformidade, observado também por Ovissipour et al. (2013), que realizaram diferentes tratamentos térmicos em mexilhões.

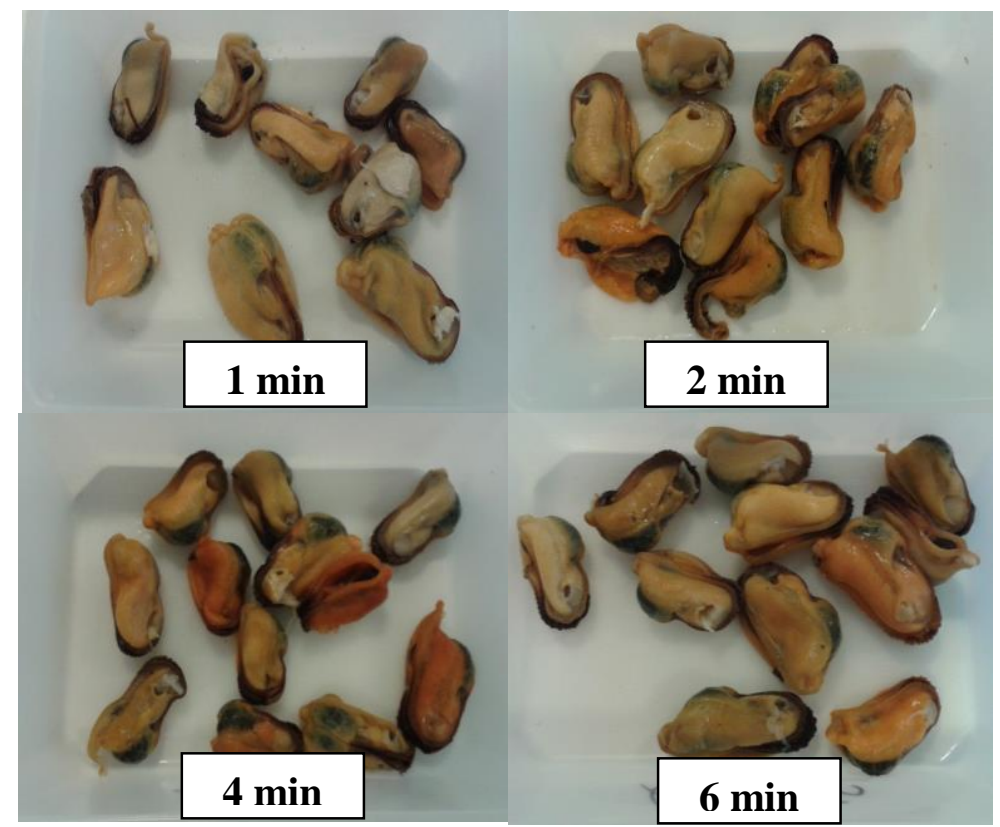

Figura 1 - Aspectos visuais e mudança de cor nos mexilhões inteiros para os diferentes tempos de tratamento térmico.

Tabela 1 - Perda de água, umidade e exsudação no interior das embalagens dos mexilhões submetidos aos diferentes períodos de tratamento térmico.

\begin{tabular}{cccc}
\hline $\begin{array}{c}\text { Tempo de } \\
\text { tratamento térmico }\end{array}$ & Perda de água (\%) & Umidade (\%) & $\begin{array}{c}\text { Exsudação no } \\
\text { interior das } \\
\text { embalagens (\%) }\end{array}$ \\
\hline $\mathbf{1}$ min & 42,14 & 77,97 & 1,79 \\
$\mathbf{2}$ min & 45,65 & 75,90 & 1,40 \\
$\mathbf{4}$ min & 51,75 & 73,24 & 0,10 \\
$\mathbf{6}$ in & 51,52 & 71,95 & 0,19 \\
\hline
\end{tabular}

A perda de água foi de $42 \%$ durante os dois primeiros minutos, com um aumento de praticamente $10 \%(51,5 \%)$ a partir dos 4 minutos de tratamento térmico, estabilizando a perda de água quando comparado ao período de 6 minutos (Tabela 1). As perdas de água causam o encolhimento da carne, pois a desnaturação proteica é o principal mecanismo envolvido, que conduz à perda da umidade. Para o mexilhão in natura a umidade de $82,78 \%$ diminui $5 \%$ no primeiro minuto, atingindo $71,95 \%$ depois 
de 6 minutos de tratamento.

\subsection{Desnaturação térmica nos mexilhões machos e fêmeas}

A Figura 2 apresenta o comportamento do gel obtido por eletroforese, onde o padrão utilizado é ilustrado com seus pesos moleculares conhecidos no lado esquerdo, enquanto as colunas codificadas com "F" se referem aos mexilhões fêmeas e o "M" aos mexilhões machos, e as numerações são as repetições, respectivamente.

A principal impressão dos padrões de proteínas no gel descreve bandas de pesos moleculares elevados, logo abaixo e acima de $250 \mathrm{kDa}$. Abaixo de $50 \mathrm{kDa}$, bandas fortes em diferentes tons são vistas, indicando a presença de muitas proteínas. Bandas coradas mais fracas são encontradas entre 15$20 \mathrm{kDa}$. Não houve diferença aparente no padrão da proteína que seja perceptível entre mexilhões machos e fêmeas. Na coluna 5 (Macho 2) a banda aparece de forma mais fraca e manchada e esta pode ser explicada por uma menor concentração de proteína na amostra carregada para o gel. Sabe-se que a cadeia pesada de miosina tem um peso molecular de cerca de $220 \mathrm{kDa}$, e a actina se encontra em torno de $42 \mathrm{kDa}$, enquanto a paramiosina é encontrada em $97 \mathrm{kDa}$. As principais proteínas relacionadas aos mexilhões são a actomiosina, a miosina, a protomiosina e o colágeno, além das proteínas dos tecidos sarcoplasmáticos e miofibrilares. A melhor identificação dessas proteínas pode ser feita repetindo as análises com concentrações precisas de proteínas carregadas para o gel para verificar se esses resultados são reprodutíveis, além de considerar que os mexilhões podem sofrer variações em sua composição devido a seu estágio de desenvolvimento. Outras investigações, como a técnica Western blotting poderia revelar mais informações sobre a actina e a miosina e sobre o mecanismo de desnaturação de proteínas nos mexilhões.

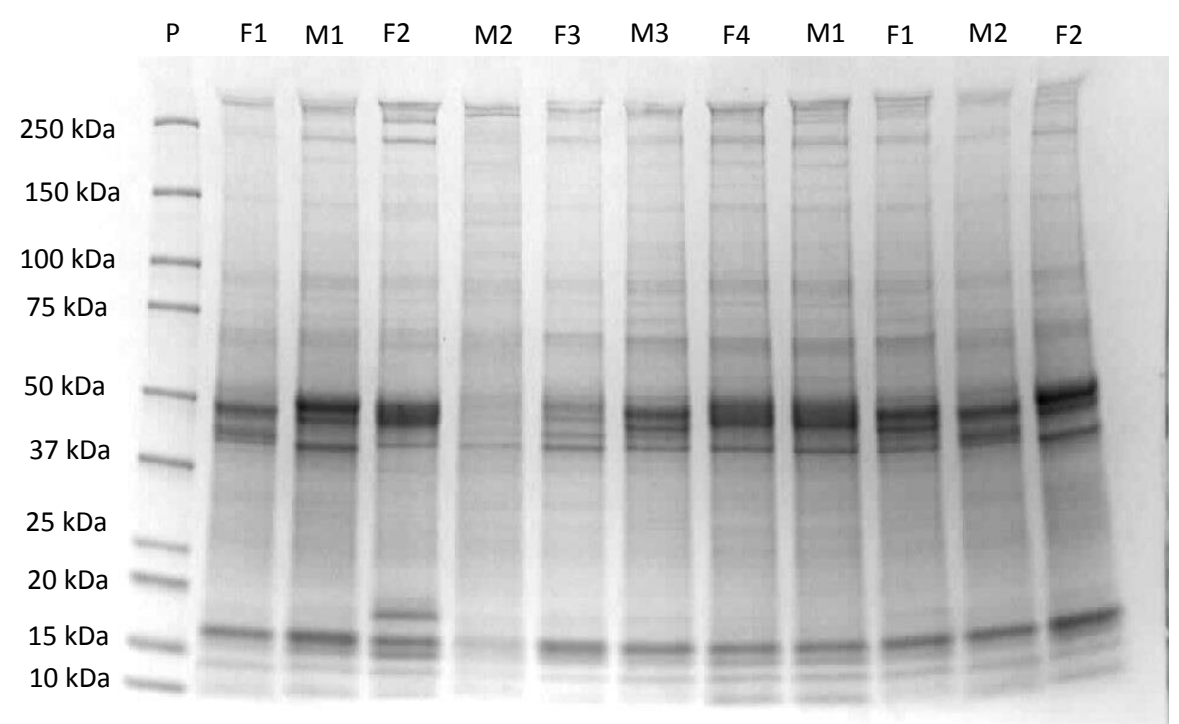

Figura 2 - Comportamento do Gel extraído dos mexilhões machos e fêmeas por eletroforese SDS- Page para mexilhões machos e mexilhões fêmeas. 


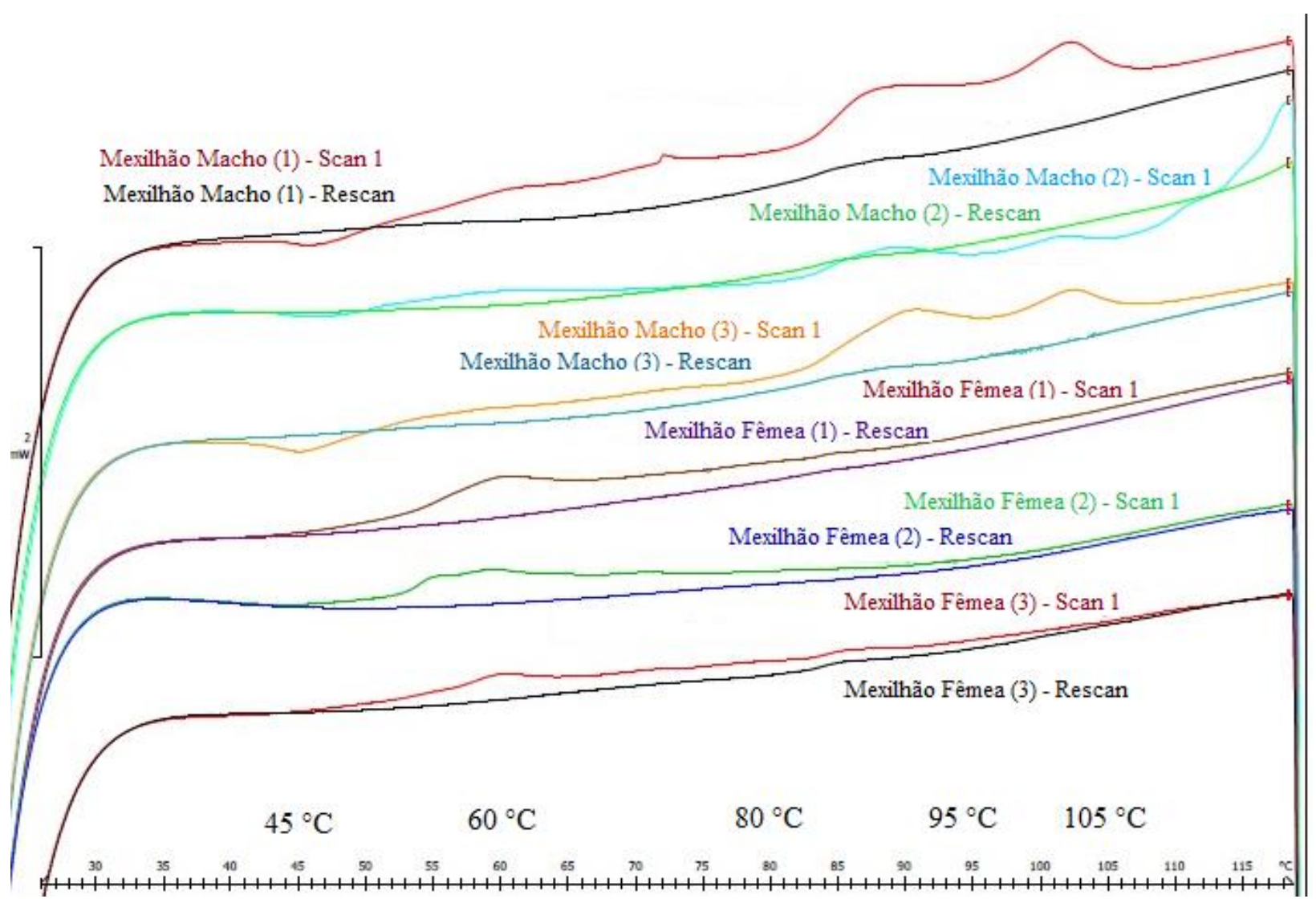

Figura 3 - Desnaturação proteica obtida pelos termogramas do DSC para os mexilhões machos e fêmeas in natura, com a realização de duas varreduras (Scan 1 e Rescan).

Os resultados mostram os termogramas obtidos para os mexilhões machos e fêmea. Na Figura 3 as três curvas superiores são para os mexilhões machos, e as três curvas inferiores são para os mexilhões fêmea. As amostras foram expostas a um aumento de temperatura de $5^{\circ} \mathrm{C}$ por minuto. Os termogramas forneceram um pico endotérmico para os mexilhões fêmeas entre $50-65{ }^{\circ} \mathrm{C}$, enquanto para o pico de mexilhões machos foi encontrado entre $85-100{ }^{\circ} \mathrm{C}$. O pico do manto do mexilhão macho apresentaram dois picos que podem indicar que dois grupos diferentes de proteína que desnaturaram a essas altas temperaturas. Estes resultados indicam a desnaturação de proteínas distintas, visto que houve diferenças na faixa de temperatura em que ocorreu a desnaturação, bem como diferente comportamento entre os gêneros estudados.

É comum a utilização da técnica DSC para descrever a desnaturação da proteína de actina e miosina nos alimentos como músculo de peixe e carne. A miosina normalmente desnatura em torno 44-57 ${ }^{\circ} \mathrm{C}$, valor inferior ao pico encontrado na fêmea, enquanto a actina desnatura em torno de 77-81 ${ }^{\circ} \mathrm{C}$, valor inferior ao pico encontrado nos mexilhões machos, no presente estudo. Sabe-se que a miosina em pescado é mais sensível aos fenômenos de desnaturação, coagulação, degradação e mudanças químicas. A paramiosina tem sido encontrada em músculos estriados de invertebrados, cobertos por uma fina camada de miosina. Os moluscos bivalves possuem uma quantidade pequena de tecidos 


\section{9 a 22 de outubro de 2014 \\ Florianópolis/SC}

conjuntivos, o que resultam em uma proporção maior de desnaturação de proteínas miofibrilares e sarcoplasmáticas em todo o mexilhão, enquanto o músculo adutor, a proteína é mais estável ao calor, desnaturando a $112{ }^{\circ} \mathrm{C}$ (Paredi et al., 1994; Ovissipour et al., 2013).

Ovissipour et al., (2013) observaram picos de desnaturação em mexilhões Mytilus edulis, porém sem diferenciação de gêneros, e encontraram três diferentes picos de desnaturação no manto do mexilhão, as temperaturas máximas de 79,85 e $87^{\circ} \mathrm{C}$, além de uma transição endotérmica no valor de $112{ }^{\circ} \mathrm{C}$, atribuído ao músculo adutor. Entretanto, neste trabalho não foi analisado o músculo adutor, apenas a carne do manto dos mexilhões macho e fêmea.

Nos resultados de SDS -PAGE não foram percebidas as diferenças entre os mexilhões machos e fêmeas, como evidenciado nas termografias. Uma possível explicação é que as proteínas diferentes que apareceram nas curvas obtidas por DSC, não puderam ser solubilizadas e com isso não foi possível ser detectadas no gel quando submetido à análise por eletroforese. Foi observado que existem variações individuais no perfil proteico entre os mexilhões, o que confirma a heterogeneidade dessa matéria prima.

Os resultados encontrados demonstram que a aplicação de temperatura, mesmo por curtos períodos, é suficiente para mudanças estruturais dos moluscos, promovendo a desnaturação proteica. A termografia realizada nos mexilhões tratados termicamente por 6 minutos apresentou ausência de picos, demonstrando que a maior parcela proteica é desnaturada. A principal consequência da desnaturação é a disponibilidade de frações proteicas sujeitas à proteólise por reações enzimáticas e/ou microbiológicas, que podem acelerar a deterioração deste produto. Por isso, recomenda-se que sejam aplicados tratamentos térmicos brandos a fim de preservar a estrutura proteica e evitar alterações indesejáveis para o consumo, como a perda excessiva de água e consequentemente perda da suculência, além da exsudação nas embalagens, que pode ser um critério de rejeição do produto pelo consumidor.

\section{CONCLUSÕES}

De forma geral, predominaram as proteínas de baixo peso molecular e as diferenças encontradas foram individuais e evidenciadas entre os gêneros somente na análises térmicas mostradas nos termogramas. Recomenda-se realizar um tratamento térmico suficiente para a remoção da carne para evitar alterações nas características físicas e sensoriais em mexilhões. É necessário investigar os tipos de proteínas presentes no mexilhão e os seus mecanismos de transformação durante os processos térmicos e na aplicação de outros processos, como alta pressão, para assim relacionar os fenômenos de desnaturação proteica com o comportamento do molusco e suas mudanças durante o armazenamento.

\section{REFERÊNCIAS}

AZANZA, M. P. V.; AZANZA, R. V.; VENTURA, S. Heat shocking of Philippine green mussels, Perna viridis. Int. J. Food Sci. Tech., v. 40, p. 689-694, 2005. 
DIAS, M. T.; SANTOS, P. C. R. F.; OLIVEIRA, L. A. T.; MARIN, V. A. Evaluation of antimicrobial sensitivity of Escherichia coli strains isolated from mussels (Perna perna linnaeus 1758). Ciênc. Tec. Alim., Campinas, v. 30, n. 2, p. 329-324, abr-jun, 2010.

ERDOGDU, F.; BALABAN, M.O.; OTWELL, W.S.; GARRIDO, L. Cook-related yield loss for Pacific white (Penaeus vannamei) shrimp previously treated with phosphates: effects of shrimp size and internal temperature distribution. J. Food Eng., v. 64, p. 297-300, 2004.

FURLAN, É. F.; GALVÃO, J. A.; SALÁN, E. O.; YOKOYAMA, V. A.; OETTERER, M. Estabilidade físico-química e mercado do mexilhão (Perna perna) cultivado em Ubatuba - SP. Ciênc. Tec. Alim., Campinas, v. 27, n. 3, p. 516-523, jul.-set., 2007.

GORINSTEIN, S.; ARANCIBIA-AVILA, P.; MONCHEVA, S.; TOLEDO, F.; TRAKHTENBERG, S.; GORINSTEIN, A.; GOSHEY, I.; NAMIESNIK, J. Changes in mussel Mytilus galloprovincialis protein profile as a reaction of water pollution. Environ. Int., v.32, p.95100, 2006.

LIMA, M. Aplicação do $\mathrm{CO}_{2}$ para aumento da vida útil de mexilhão Perna perna (L) e Mytillus edulis: processo de pré-solubilização e acondicionamento sob atmosfera modificada ativa. 229 p. Tese (Doutorado) - Universidade Federal de Santa Catarina, Centro Tecnológico, Programa de Pós-Graduação em Engenharia de Alimentos, Florianópolis, 2014.

MASNIYOM, P.; BENJAMA, O.; MANEESRI, J. Extending the shelf-life of refrigerated green mussel (Perna viridis) under modified atmosphere packaging. Song. J. Sci. Tech., v. 33(2), p. 171179, 2011.

OLIVEIRA, J.; CUNHA, A.; CASTILHO, F.; ROMALDE, J. L.; PEREIRA, M. J. Microbial contamination and purification of bivalve shellfish: Crucial aspects in monitoring and future perspectives - A mini-review. Food Cont., v. 22, p. 805-816, 2011.

OVISSIPOUR, M.; RASCO, B.; TANG. J.; SABLANI, S. S. Kinetics of quality changes in whole blue mussel (Mytilus edulis) during pasteurization. Food Res. Int., v. 53, p. 141-148, 2013.

PAREDI, M. E.; TOMAS, M. C.; CRUPKIN, M.; ANON, M. C. (1994). Thermal denaturation of Aulacomya ater ater (Molina) myofibrillar proteins: A differential scanning calorimetric study. $J$. Agr. Food Chem., v.42, p.873-877, 1994.

PULGAR, J. S.; GÁSQUEZ, A.; RUIZ-CARRASCAL, J. Physico-chemical, textural and structural characteristics of sous-vide cooked pork cheeks as affected by vacuum, cooking temperature, and cooking time. Meat Sci., v. 90, p. 828-835, 2012.

SKIPNES, D.; ØSTBY, M. L.; HENDRICKX, M. E. A method for characterizing cook loss and water holding capacity in heat treated cod (Gadus morhua) muscle. J. Food Eng., v. 80, p. 10781085, 2007. 